\title{
Analysis of Cutting Tools Durability Compared with Standard ISO 3685
}

\author{
Anton Panda, Ján Duplák, and Karol Vasilko
}

\begin{abstract}
Quality and accuracy in engineering is described by means of standards ISO. One of these standards is standard ISO 3685. The main part of this standard is $T-v_{\mathrm{c}}$ dependence for various cutting materials. Standard ISO 3685 contains main properties and characteristics of three most important cutting materials those are used in engineering practice. These cutting materials are used for cutting tools made of high speed steel, cutting ceramic and sintered carbide. The standard ISO 3685 prescribes instructions to creation of $T-v_{c}$ dependence for defined cutting materials. Paper describes process how to define $T-v_{c}$ dependence for cutting tools made of high speed steel, cutting ceramic and sintered carbide, because were found deficiencies in valid standard ISO 3685 .
\end{abstract}

Index Terms-Analysis, cutting tools, durability, taylor

\section{INTRODUCTION}

Verification of standards is very difficult process. Primary factor of each new discovery or piece of knowledge is experiment. After analyzing of outputs final dependencies can be described. In technical sciences are descriptions for each experiment, realization of process or adequate choice of cutting tools, materials, technological conditions, cutting parameters and theirs application [1], [2].

In engineering can be used for experiments a lot of different technological operations. One of these operations is turning.

Turning is the most basic process in machining, because it forms $30 \%$ from all technologies of machining. [3], [4], [5].

In the turning there are many types of cutting tools used made of different materials. Some of these materials are high speed steel, cutting ceramic, sintered carbide.

High speed steel (HSS) is a subset of tool steels, usually used in tool bits and cutting tools. It is superior to the older high carbon steel tools used extensively through the 1940s in that it can withstand higher temperatures without losing its hardness. This property allows HSS to cut faster than high carbon steel, hence the name high speed steel [6], [7].

Sintered carbide is unique combination of strength, hardness and toughness satisfies the most demanding applications [8], [9].

A key feature of the sintered carbide is the potential to vary its composition so that the resulting physical and chemical properties ensure maximum resistance to wear, deformation, fracture, corrosion, and oxidation [6], [10], [11].

Ceramic cutting tools have been in use for approximately

Manuscript received June 3, 2012; revised July 4, 2012

The authors are with the Department of Manufacturing Technologies FVT TU in Košice with seat in Prešov, 080 01Prešov, Slovakia (e-mail: anton.panda@tuke.sk,jan.duplak@tuke.sk, karol.vasilko@tuke.sk).
90 years. However, as new cutting tools were developed, new materials that demanded even more rigorous machining requirements were also developed [12], [13].

Interest in ceramics as a high speed cutting tool material is based primarily on favorable material properties. As a class of materials, ceramics possess high melting points, excellent hardness and good wear resistance. Ceramics are also chemically inert against most workmetals [4].

\section{General Information About $V B=\mathrm{f}\left(\tau_{\mathrm{s}}\right)$ Dependence}

Graphics dependence $V B=\mathrm{f}\left(\tau_{\mathrm{s}}\right)$ for different cutting speeds was described with Frederick Winslow Taylor in 1906. Taylor defined that the criterion of blunting was the same for all curves $V B_{\mathrm{k}}$. Dependences that are described by Taylor are relevant only for high speed steel, because in that time high speed steel was only available for Taylor experiments [14].

Knowledge defined by Taylor is used in standard ISO 3685. Standard ISO 3685 obtains tests of durability of cutting tools for workpieces made of steel and cast iron. This standard includes only cutting tools made of high cutting steel, sintered carbide and cutting ceramic. Standard is valid only for conditions, when the criterion of durability is defined as tool wear [15].

\section{PRIMARY OUTPUTS FROM ANALYSIS OF STANDARD ISO 3685}

The standard ISO 3685 describes for all cutting materials common $T-v_{\mathrm{c}}$ dependence. Current valid relation of $T-v_{\mathrm{c}}$ dependence is described by Taylor formed basics of standard ISO 3685. $T-v_{\mathrm{c}}$ dependence was designed according to Taylor in logarithmic scale [16].

Very significant problem in standard ISO 3685 is evaluation of results. Characteristics and dependences for all cutting materials are same [15].

\section{The Basic Methods For EVAluation of Results ACCORDING TO STANDARD ISO 3685}

Standard ISO 3685 describes more methods for solution of $T-v_{c}$ dependence. For each method that is described in standard there should be exactly identified procedure for obtaining of tested dependences [17].

Standard ISO 3685 indicates these methods to obtain the results:

1) To toggle the line through measured points (approximation)

2) Method of least squares, Guess evaluation

3) Interpolation of dependence into unmeasured field of cutting speeds 


\section{DESCRIPTION OF $T-V_{\mathrm{C}}$ DEPENDENCE}

Taylor defined $T-v_{\mathrm{c}} \quad$ dependence according to experiments made with high speed steel. These tests according to standard ISO 3685 are valid for all cutting materials. The standard ISO 3685 contains information about $T-v_{\mathrm{c}}$ dependences for high speed steel, sintered carbide and cutting ceramic [17].

Lot of authors think that's not true and this paper describes experiments of turning with cutting tools made of high speed steel, cutting ceramic and sintered carbide and testing of tool wear.

\section{MAchining Long-Term Test Method}

Essentially there is only one machining long-term test method. Criterion is value of cutting speed and it is done by turning or milling with described constant cutting parameters, type of cutting tool with defined geometry and graduated cutting speeds to the optimal tip blunting. This test is considered as basic and this test set measuring objectivity of machinability for others tests. Disadvantage of this test is consumption of workpieces and time consumption [5].

\section{A. Description of Machining Long-Term Test Method:}

1) Time measurement process of depreciation on back of tool $V B_{\mathrm{B}}$, for few value of cutting speeds at constant cutting parameters and construction curve of blunting.

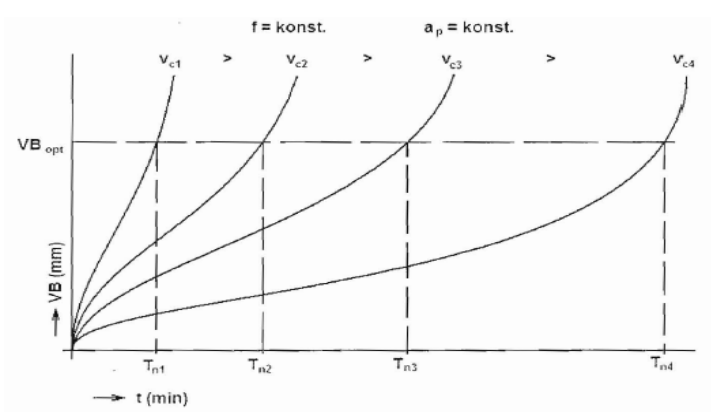

Fig. 1. Curve of blunting for variable cutting speeds [16].

2) Specification criterion of depreciation $V B_{\text {opt }}$ and determination of tip durability for each cutting speed.

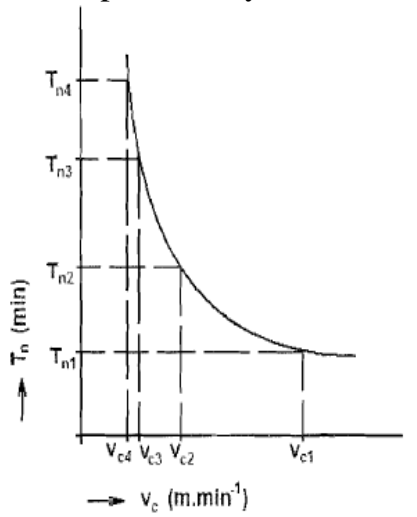

Fig. 2. Determination of particular durability by the criterion of depreciation [16].

3) Construction $T_{\mathrm{n}}=\mathrm{f}\left(v_{\mathrm{c}}\right)$ dependence in logarithmic scale and determination index of machinability for selected durability after comparison of cutting speed of tested material and etalon material.

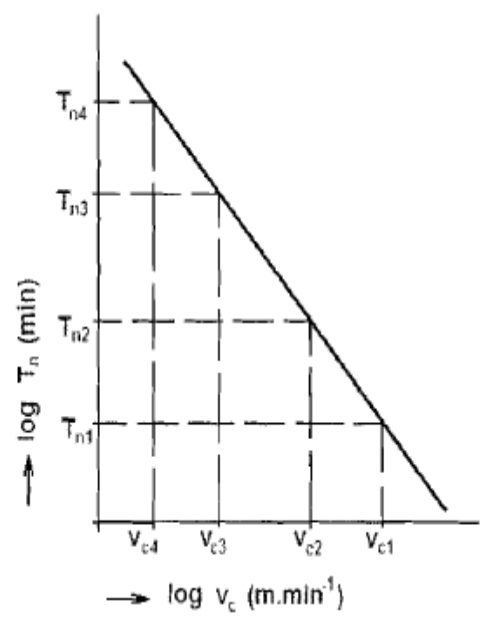

Fig. 3. $T$ - $v_{\mathrm{c}}$ dependence in logarithmic scale [16].

\section{DEFINITION OF THE TECHNOLOGICAL SYSTEM AND THE SINGLE PARTS OF EXPERIMENT}

First part of experiment contains specification of technological system. Technological system is for valid experiment very important and it contains machine-tool-workpiece.

Workpieces for experiments are made from steel C45. Experimental material is with specific material list with guaranteed chemical structure.

These experiments were made under defined technological conditions. Tool durability was proven with kinetic machining long-term test method. Experiment inputs were workpieces with equal diameters those were used at turning process. For each cutting speed the diameter should have the same value, because examined material has different consistency in different depth. Experiment was finished once wear criterion was reached.

\section{TeChnological Conditions Used for High SPEed STEEL}

$v_{\mathrm{c}}=3,1-89 \mathrm{~m} \cdot \mathrm{min}^{-1} ; a_{\mathrm{p}}=0,5 \mathrm{~mm} ; f=0,1 \mathrm{~mm} ;$ $r_{\varepsilon}=0,5 \mathrm{~mm} ; \kappa_{\mathrm{r}}=75^{\circ} ; \kappa_{\mathrm{r}}^{\prime}=15^{\circ} ; V B=0,3 \mathrm{~mm} ; \gamma_{\mathrm{o}}=-6^{\circ}$

TABLE I: RESULTS OF $T-v_{\mathrm{c}}$ DEPENDENCE FOR HSS

\begin{tabular}{|c|c|}
\hline $\boldsymbol{v}_{\mathbf{c}}, \mathbf{m} \cdot \mathbf{m i n}^{-\mathbf{1}}$ & $\boldsymbol{T}, \mathbf{m i n}$ \\
\hline 3,1 & 90 \\
\hline 10 & 35 \\
\hline 11,8 & 25 \\
\hline 18,9 & 24 \\
\hline 56 & 2,5 \\
\hline 89 & 1 \\
\hline
\end{tabular}

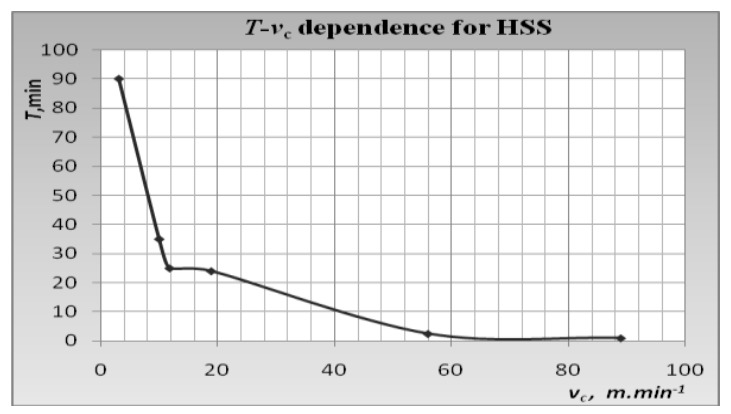

Fig. 4. $T-v_{\mathrm{c}}$ dependence for HSS at $V B=0,3 \mathrm{~mm}$ (linear scale). 


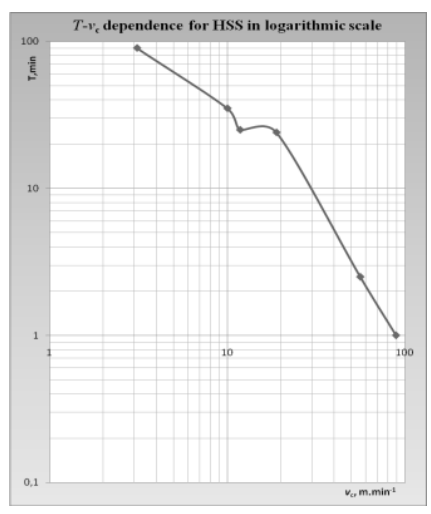

Fig. 5. $T$ - $v_{\mathrm{c}}$ dependence for HSS at $V B=0,3 \mathrm{~mm}$ (logarithmic scale).

\section{TeChNOLOGical CONDITIONS USED For CUTTING CERAMIC $\left(\mathrm{Al}_{2} \mathrm{O}_{3}\right)$}

$v_{\mathrm{c}}=2,5-504 \mathrm{~m} \cdot \mathrm{min}^{-1} ; a_{\mathrm{p}}=0,3 \mathrm{~mm} ; \quad f=0,1 \mathrm{~mm} ;$ $r_{\varepsilon}=0,8 \mathrm{~mm} ; \kappa_{\mathrm{r}}=80^{\circ} ; \kappa_{\mathrm{r}}^{\prime}=10^{\circ} ; V B=0,3 \mathrm{~mm}$;

TABLE II: RESULTS OF $T-v_{\mathrm{c}}$ DEPENDENCE FOR $\mathrm{Al}_{2} \mathrm{O}_{3}$

\begin{tabular}{|l|l|l|l|}
\hline $\boldsymbol{v}_{\mathbf{c}}, \mathbf{m} \cdot \mathbf{m i n}^{-\mathbf{1}}$ & $\boldsymbol{T}, \mathbf{m i n}$ & $\boldsymbol{v}_{\mathbf{c}}, \mathbf{m} \cdot \mathbf{m i n}^{-\mathbf{1}}$ & $\boldsymbol{T}, \mathbf{m i n}$ \\
\hline 2,5 & 50 & 124 & 28 \\
\hline 8,5 & 32 & 139 & 28 \\
\hline 9 & 24 & 140 & 25 \\
\hline 15,5 & 19 & 150 & 20,5 \\
\hline 17,2 & 18 & 155 & 20 \\
\hline 20 & 17 & 180 & 15 \\
\hline 30 & 15,5 & 220 & 10 \\
\hline 47 & 27 & 234 & 9 \\
\hline 48 & 27 & 250 & 9 \\
\hline 56 & 27 & 270 & 9 \\
\hline 78 & 28,5 & 369 & 7,5 \\
\hline 100 & 30 & 430 & 6,4 \\
\hline 123 & 29 & 504 & 6 \\
\hline
\end{tabular}

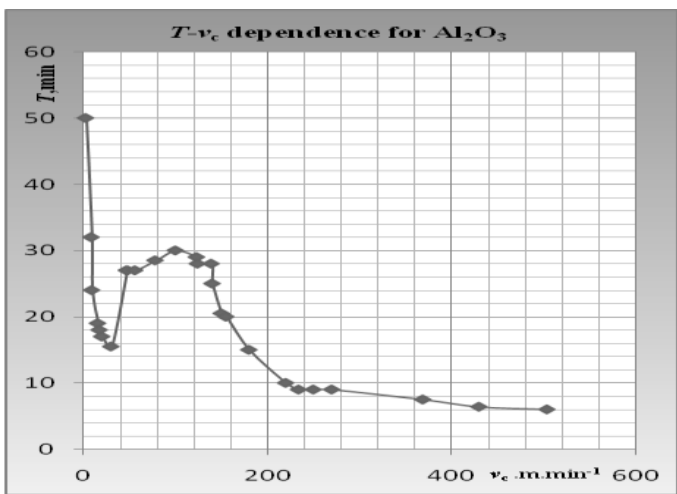

Fig. 6. $T$ - $v_{\mathrm{c}}$ dependence for $\mathrm{Al}_{2} \mathrm{O}_{3}$ at $V B=0,3 \mathrm{~mm}$ (linear scale).

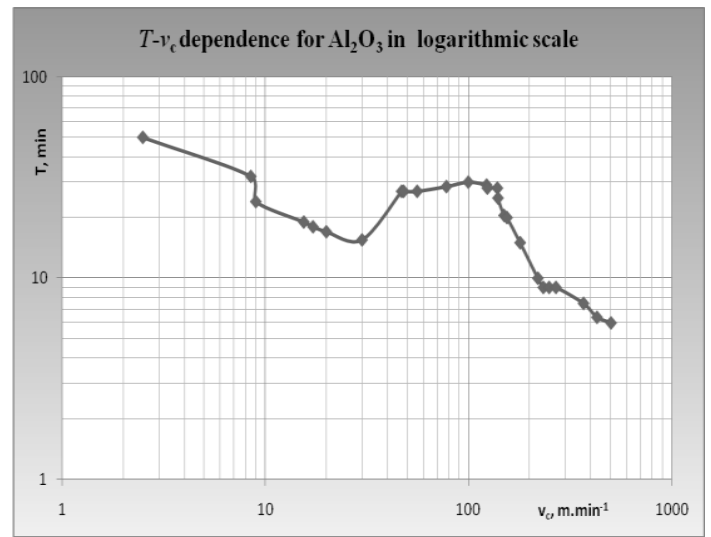

Fig. 7. $T$ - $v_{\mathrm{c}}$ dependence for $\mathrm{Al}_{2} \mathrm{O}_{3}$ at $V B=0,3 \mathrm{~mm}$ (logarithmic scale).

\section{Technological Conditions Used for Sintered CARBIDE (P20+TIN)}

$v_{\mathrm{c}}=7-300 \mathrm{~m} \cdot \mathrm{min}^{-1} ; a_{\mathrm{p}}=0,1 \mathrm{~mm} ; \quad f=0,3 \mathrm{~mm}$; $r_{\varepsilon}=0,8 \mathrm{~mm} ; \kappa_{\mathrm{r}}=80^{\circ} ; \kappa_{\mathrm{r}}^{\prime}=10^{\circ} ; V B=0,3 \mathrm{~mm} ;$

TABLE III: RESULTS OF $T-v_{\mathrm{c}}$ DEPENDENCE FOR $\mathrm{Al}_{2} \mathrm{O}_{3}$

\begin{tabular}{|l|l|l|l|}
\hline $\boldsymbol{v}_{\mathbf{c}}, \mathbf{m} \cdot \mathbf{m i n}^{-\mathbf{1}}$ & $\boldsymbol{T}, \mathbf{m i n}$ & $\boldsymbol{v}_{\mathbf{c}}, \mathbf{m}_{\mathbf{m i n}} \mathbf{- 1}^{-1}$ & $\boldsymbol{T}, \mathbf{m i n}$ \\
\hline 7 & 220 & 90 & 225 \\
\hline 9 & 100 & 100 & 210 \\
\hline 11 & 70 & 110 & 205 \\
\hline 22 & 60 & 120 & 150 \\
\hline 40 & 115 & 140 & 66 \\
\hline 44 & 125 & 200 & 40 \\
\hline 60 & 175 & 240 & 25 \\
\hline 70 & 200 & 300 & 17 \\
\hline
\end{tabular}

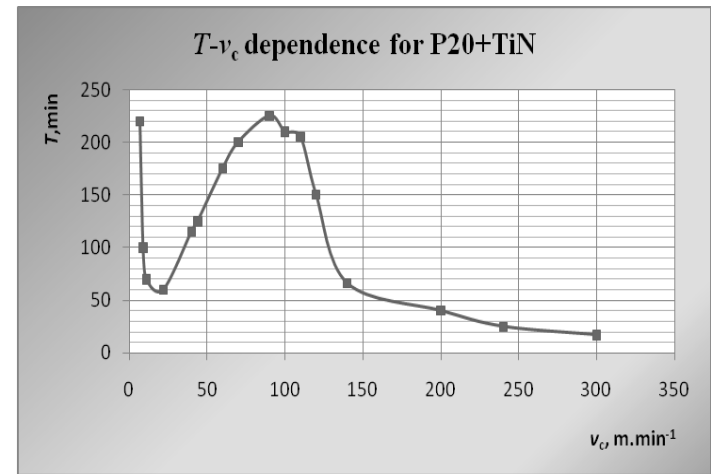

Fig. 8. $T$ - $v_{\mathrm{c}}$ dependence for $\mathrm{P} 20+\mathrm{TiN}$ at $V B=0,3 \mathrm{~mm}$ (linear scale).

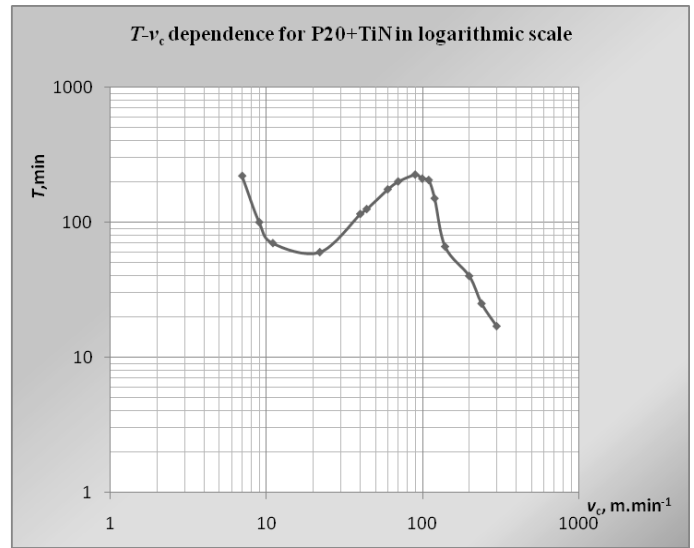

Fig. 9. $T-v_{\mathrm{c}}$ dependence for $\mathrm{P} 20+\mathrm{TiN}$ at $V B=0,3 \mathrm{~mm}$ (logarithmic scale).

\section{CONCLUSION}

Material for cutting tools defines their machining properties. Testing properties of those materials are very important, because their properties may be different than properties defined in standards ISO. Within this paper there were tested cutting materials made of high speed steel, cutting ceramic $\left(\mathrm{Al}_{2} \mathrm{O}_{3}\right)$ and sintered carbide $(\mathrm{P} 20+\mathrm{TiN})$ of which cutting properties are defined in ISO 3685.

In previous parts (VII,IX,X) were determined $T-v_{\mathrm{c}}$ dependences for defined cutting tools. These $T-v_{\mathrm{c}}$ dependences were described by means of measured values from experiments. For each cutting material were created two graphs. First graph was created in linear scale and second graph was created according to Taylor and ISO 3685 in logarithmic scale. Following graphs (Fig. 10-12) show differences between ISO 3685 and results of experiments. 


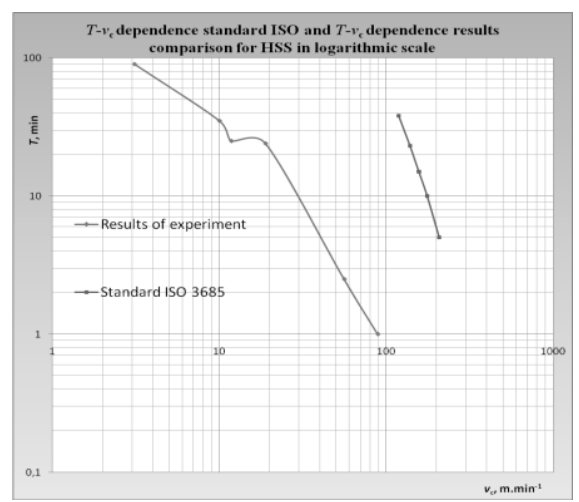

Fig. 10. Standard ISO and experiment results comparison for HSS.

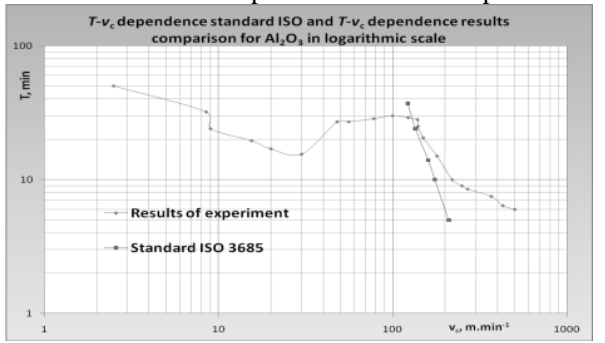

Fig. 11. Standard ISO and experiment results comparison for $\mathrm{Al}_{2} \mathrm{O}_{3}$.

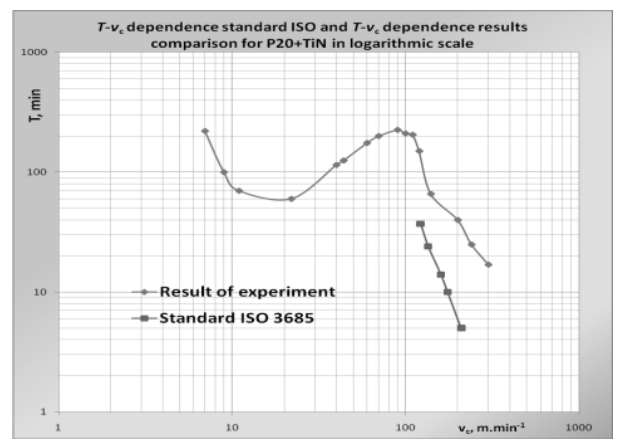

Fig. 12. Standard ISO and experiments results comparison for P20+TiN.

There is no linear dependence for cutting materials made of cutting ceramic and sintered carbide as it is presented in ISO 3685. Differences between ISO 3685 and $T-v_{\mathrm{c}}$ dependences from results of experiments are appreciable as graphical evidenced on Fig. 11and Fig. 12. ISO 3685 is valid only for cutting tools made of high speed steel. Dependence defined on the base Taylor in ISO 3685 is with minor differences linear only for this cutting material. The cause of minor differences may be several factors for example small amount of experiments, measurement errors or different measuring devices. The main reason of validity ISO 3685 for cutting materials made of high speed steel is fact, that when Taylor created $T-v_{\mathrm{c}}$ dependence was for experiments available only high speed steel and others cutting materials were to the ISO 3685 supplemented. $T-v_{\mathrm{c}}$ dependence for cutting ceramic and sintered carbide that was defined in ISO 3685 cannot be valid, because for these cutting materials were not executed tests, but $T-v_{\mathrm{c}}$ dependence was supplemented according $T-v_{\mathrm{c}}$ dependence for high speed steel defined by Taylor in 1906. Deeper exploration of these problems is very important. Experiments need to be repeated with accurately defined technological parameters throughout available range of cutting speeds and analysed through valid ISO 3685 .

\section{ACKNOWLEDGMENT}

The authors would like to thank the VEGA grant agency for supporting research work the projects: VEGA\#1/0047/10

\section{REFERENCES}

[1] J. Jurko, "Monitoring and Diagnosis of Drill Wear and the Thermodynamic Phenomenas of Material Removal by Drilling of Stainless Steels," Experimental Analysis of Nano and Engineering Materials and Structures, Springer vol. 37, 2007, pp.77-78.

[2] L. Straka, S. Fabian, and S. Hloch, "The modeling and simulation of quality in process EDM cutting with wire electrode," in Proceedings of the 5th International Conference of DAAAM Baltic, Tallinn, Estonia, University of Technology Tallinn, 20 - 22 April 2006, pp. 167-170.

[3] L. Straka, M. Rimár, I. Čorný, and J. MIHALČOVÁ, "Increasing of Operational Reliability of Technical System", in proc. DAAAM 2011, DAAAM International Vienna, 2011, pp.1089-1090.

[4] J. Mačala and I. Pandová, "Natural zeolite-clinoptilolite - raw material serviceable in the reduction of toxical components at combustion engines noxious gases," Gospodarka Surowcami Mineralnymi, vol. 23, no. 4, pp. 19-25, 2007.

[5] I. Pandová, L. Knapčíková, and P. Oravec, "Recycling of mix plastic waste from wrecks a cars," Studia i Materialy, vol. 26-29, no. 1-2, pp. 53-58, 2010

[6] E. Isakov, Cutting Data for turning of steel, Industrial Press, Inc. 989 Avenue of the Americas New York, NY 10018, pp. 316, 2009.

[7] J. R. Davis, Materials. ASM Specialty Handbook, ASM International, Materials Park, Ohio, pp. 501, 1998

[8] Y. A. Helmi and H. El-Hofy, Machining Technology-Machine Tools and Operations, CRC Press, pp. 398, 2008.

[9] J. T. Black and R. A. Kohser, Degarmo's Materials \& Processes in Manufacturing, Wiley India Private Limited, pp. 1032, 2007.

[10] B. S. P. Nagendra and R. K. Mittal, Elements of Manu facturing Proces, Prentice-Hall of India Private Limited, pp. 496, 2006.

[11] H. Tschätsch, Applied Machining Technology, Original German edition published by Vieweg, Wiesbaden, pp. 398, 2007.

[12] E. D. Whitney, Ceramic Cutting Tools, William Andrew Publishing/Noyes, pp. 353, 1994.

[13] M. C. Shaw, Metal Cutting Principles, Oxford University Press, pp. $651,2005$.

[14] J. Duplák, Identification of Comprehensive T-vc Dependence, Diploma Thesis, Prešov FVT, pp. 106, 2010

[15] K. Vasilko, Theory and Practise of Splinter Machining, Prešov FVT, pp. 546, 2009.

[16] T. Gondová, I. Pandová, S. Tkáčiková, and P. Oravec, "Možnosti aplikácie prírodného zeolitu-klinoptilolitu na adsorpciu toxických zložiek výfukových plynov," Chemické Listy, vol. 97, no. 8, pp. 820, 2003.

[17] STN ISO 3685:Tool-Life Testing with Single-Point Turning Tools, 1999 